\title{
First report of Ichthyophonus disease in wild and cultured sea bass Dicentrarchus labrax from the Spanish Mediterranean area
}

\author{
A. Sitja-Bobadilla, P. Alvarez-Pellitero \\ Instituto de Acuicultura de Torre de la Sal (C.S. I. C.), Ribera de Cabanes, 12595, Castellón, Spain
}

\begin{abstract}
Microscopical examination of fresh smears and thin sections of different organs from wild and cultured sea bass Dicentrarchus labrax, collected in the Spanish Mediterranean area, revealed the presence of the 'fungus' Ichthyophonus sp. Prevalence was higher for cultured fish $(24.4 \%)$ than for wild ones $(14 \%)$. A seasonal pattern of infection, which seemed to be related to temperature, was evident for wild and cultured sea bass. Infection levels increased with host age and were higher for males. Well-vascularised organs were the most frequently infected. Endospores, resting spores, and germinating spores were observed. Granulomas (with intense fibrotic reactions that encapsulated the parasite), involving macrophages, fibrocytes, and eosinophilic granular cells, were the most common lesions seen. This first report of Ichthyophonus sp. in sea bass confirms the importance of the disease in marine fish, especially under culture conditions.
\end{abstract}

Ichthyophonus sp. induced disease was first described by Hofer (1893) from cultured brown trout Salmo trutta and brook trout Salvelinus fontinalis in Germany. Plehn \& Mulsow (1911) described the fungal nature of the etiologic agent, and named it Ichthyophonus hoferi. Today, however, the taxonomic position of the agent remains uncertain (McVicar 1982).

This agent is an obligate parasite that produces systemic infections in a wide range of marine fishes from a variety of habitats. It also occurs occasionally in freshwater fishes. Ichthyophoniasis, the disease caused by the parasite, has mostly been reported from the North Atlantic region (Fish 1934, Powles et al. 1968, Sindermann 1970, Hendricks 1972, Agius 1978, Timur \& Timur 1984, McVicar \& McLay 1985). However, it has also been reported from waters around Japan (Miyazaki \& Kubota 1977, Chien et al. 1979), the Mediterranean (Reichenback-Klinke 1973), the
Gulf of Mexico (Couch 1985), and South-Africa (Paperna 1986).

In the present paper, the first finding of ichthyophoniasis in wild and cultured sea bass Dicentrarchus labrax is reported. Data on the prevalence and intensity of infection, as well as on the host/parasite relationship are given.

Materials and methods. A total of 228 sea bass Dicentrarchus labrax were necropsied and examined for the parasite. Of these, 101 were wild fish, captured monthly during 1986 from the delta of the River Ebro, Spain, and 127 came from a cultured stock, sampled between December 1985 and February 1988. The latter was maintained under a controlled photoperiod in running seawater ( $37.8 \%$ salinity) at ambient temperature.

After necropsy, fresh smears of organs were examined by light microscopy. Resting spores and other stages were observed using fresh material. Thin sections of infected tissues were also prepared using routine histological techniques and were stained with hematoxylin and eosin ( $\mathrm{H} \& \mathrm{E}$ ), McManus-light green method, or Mallory's stain. Occasionally, very thin sections ( 1 to $3 \mu \mathrm{m}$ ) were obtained from material fixed with $2.5 \%$ glutaraldehyde. These were embedded in Historesin (LKB) and stained with toluidine blue (TB).

Infection intensity was evaluated semiquantitatively using a scale of + to ++++++ . The scale was based on the number of resting spores or other stages seen per field and on the number of organs infected.

A 2 -way test of independence $\left(\chi^{2}\right.$ at $\left.p=0.05\right)$ was used to analyze the influence of both host age and sex on the infection rate (Sokal \& Rohlf 1981). 
Results and discussion. Parasite morphology: The developmental stage most frequently observed was the spherical multinucleated cell, variously referred to as the resting spore (Neish \& Hughes 1980), the multinucleated spherical body (Okamoto et al. 1985) or the M-spore (Paperna 1986) (Figs. 1 and 3). This developmental stage (20 to 94 um diam.) was enclosed in a thick, strongly PAS-positive wall.

So-called endospores or uni- or binucleated bodies ( 8 to $11 \mathrm{um}$ diam.) were also found. They occurred within large granulomas that contained various generations of the parasite (Figs. 2 and 9 ) or were isolated within the affected tissue (Fig. 8). They were similar to the forms described by Okamoto et al. (1985) in in vitro experiments, but have also been reported in natural infections by Miyazaki \& Kubota (1977), McVicar \& McLay (1985) and Paperna (1986), the last author referring to them as S-spores. Occasionally, spherical multinucleated 'hyphae' were also observed (Figs. 4 to 7 ).

Identification of the parasite to the species level was not possible, and, as already indicated, even its taxonomic affinities are uncertain (McVicar 1982). Despite this, the developmental stages observed by us were the
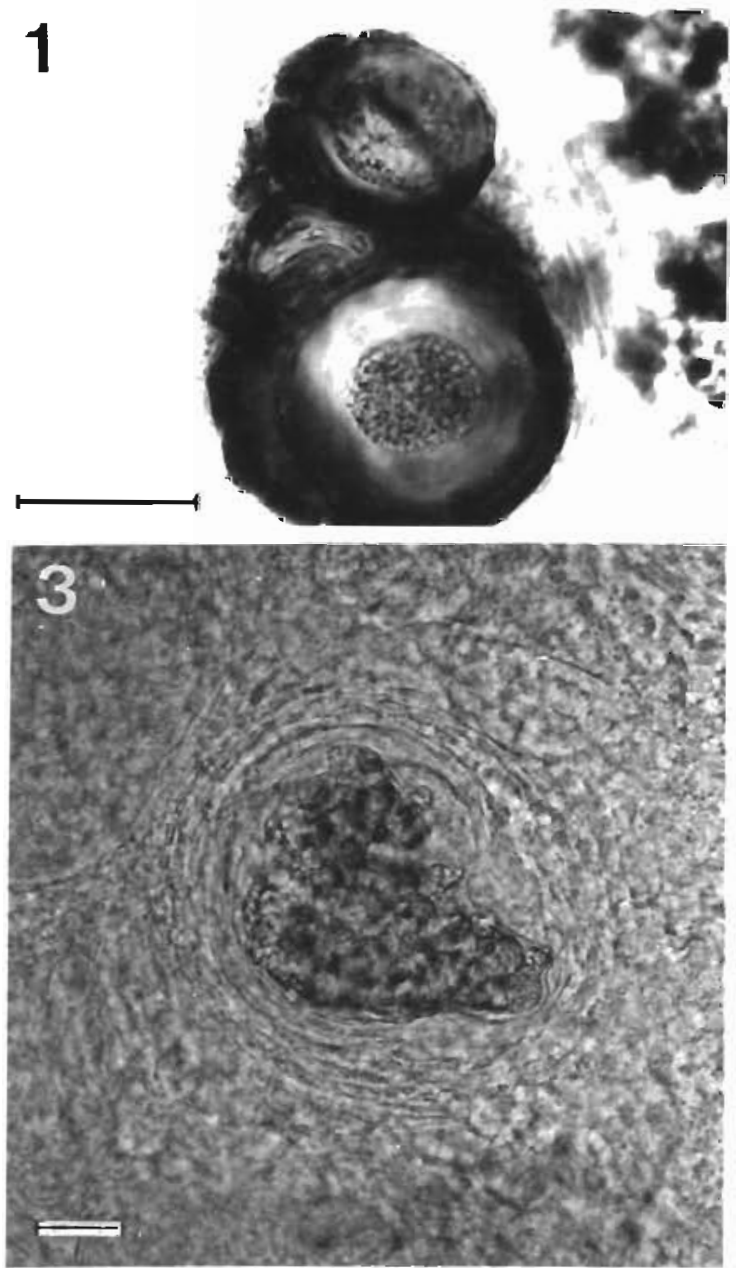

same as those described by other authors for Ichthyophonus sp. in natural (Chien et al, 1979, McVicar \& McLay 1985, Paperna 1986) and experimental (McVicar \& McLay 1985, Okamoto et al. 1987) infections.

\section{Host-parasite relationship:}

(1) Prevalence in wild and cultured fish. The overall prevalence of the parasite was moderate in wild sea bass $(14 \%)$ and not unlike that reported for natural populations of various marine teleosts from different geographical areas (Lauckner 1984). On the other hand, the higher prevalence of the parasite observed in our cultured sea bass $(24.4 \%)$, may indicate that culture conditions (high density) favour development of the infection, an ominous implication for aquaculture.

For wild sea bass. the seasonal variations in infection rate followed a bimodal pattern, with maxima in spring and autumn (and a marked peak in November) and a minimum $(0 \%)$ in summer (Fig. 10). For cultured fish, seasonal variations were more irregular, but the bimodal pattern was also observed. The pattern seemed to be related to temperature, since maxima occurred when the temperature was between 11 and $16^{\circ} \mathrm{C}$, and the minimum occurred when the temperature reached $28^{\circ} \mathrm{C}$.

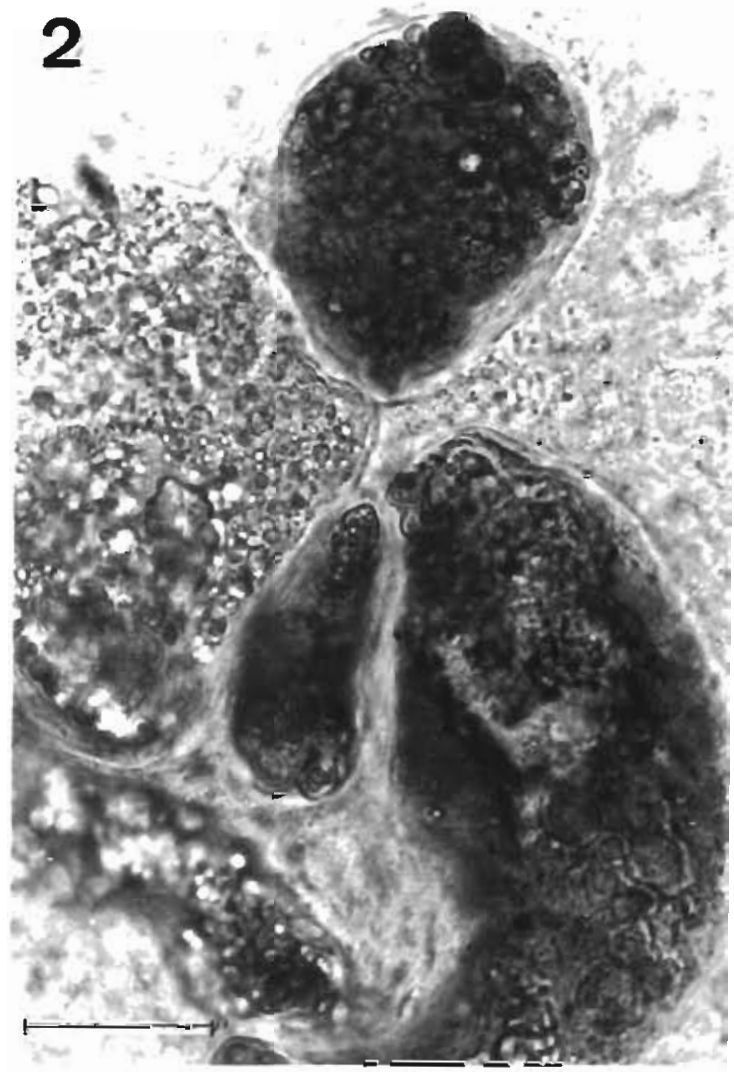

Figs 1 to 3. Dicentrarchus labrax. Fresh preparations of spleen and kidney infected by Ichthyophonus $\mathrm{sp}$., of showing granulomata with different parasite developmental stages. Note the fibrotic reaction in a $0+$ fish (Fig. 3). Scale bars $=$ $30 \mathrm{um}$ 

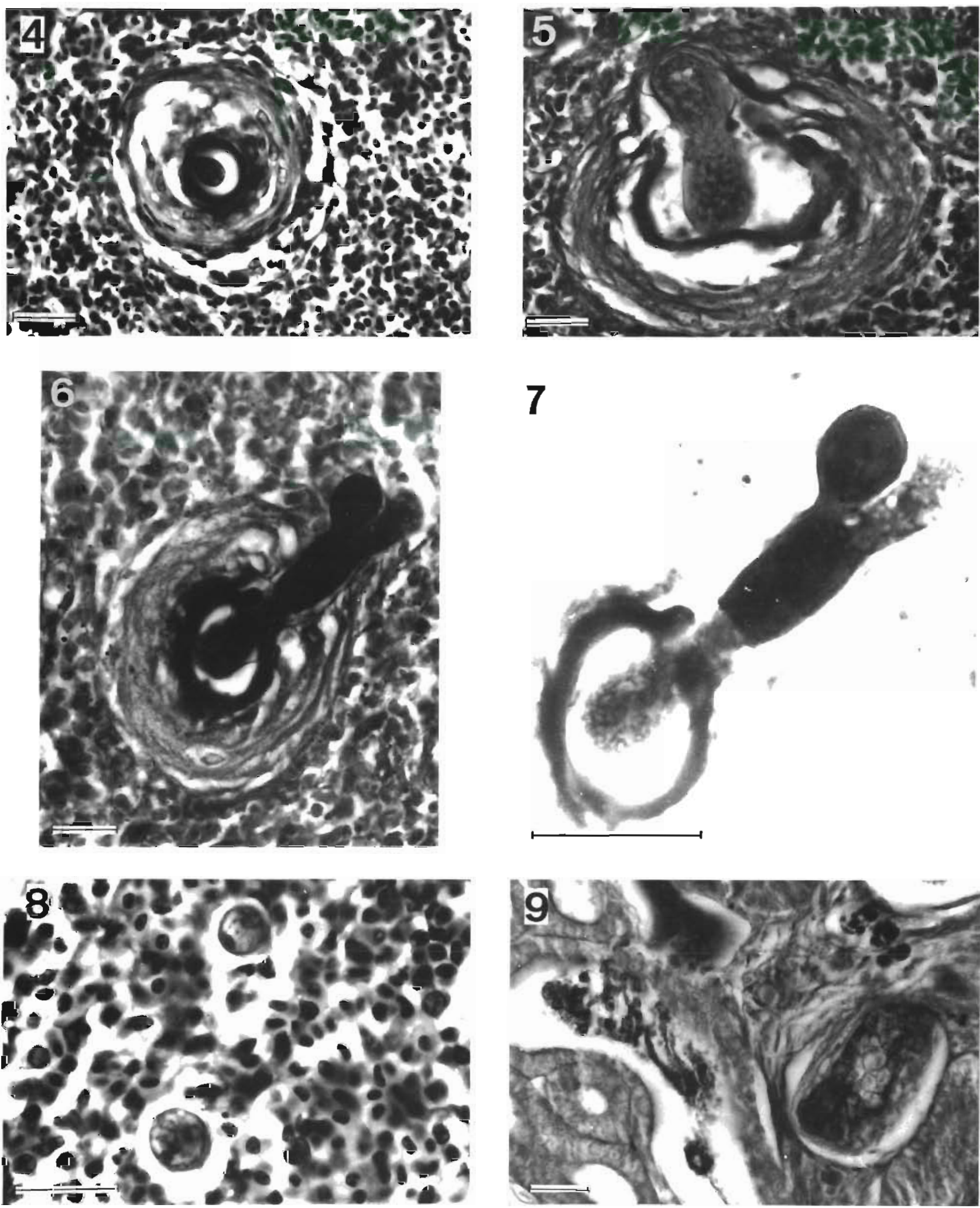

Figs. 4 to 9. Ichthyophonus sp. in Dicentrarchus labrax. Figs. 4 to 7. Sequential post mortem germination in spleen: hyphae growing through the spore wall (Figs. 4 and 5) and the fibrotic capsule (Fig. 6) branch into 2 and emerge to from a cyst (Fig. 7) Fig. 8. Spherical binucleated bodies in spleen. Fig. 9. Affected kidney of juvenile fish with different developmental stages in the tubular lumen and interstitia. Stains are: hematoxylin and eosin (Figs. 4 and 8), Mallory (Fig. 5), McManus (Figs. 6, 7 and 9). 
Table 1. Dicentrarchus labrax. Influence of sex in wild and cultured sea bass on the rate of infection by Ichthyophonus sp. Asterisk incticates statistically significant differences at $p=0.05$

\begin{tabular}{|c|c|c|c|c|c|c|}
\hline \multirow[t]{2}{*}{ Group } & \multicolumn{3}{|c|}{ Males } & \multicolumn{3}{|c|}{ Females } \\
\hline & No. examined & No. infected & $\%$ Infection & No. examined & No. infected & $\%$ Infection \\
\hline Wild & 40 & 8 & 20.0 & 61 & 6 & 9.8 \\
\hline Cultured ${ }^{*}$ & 62 & 21 & 33.8 & 38 & 5 & 13.2 \\
\hline
\end{tabular}

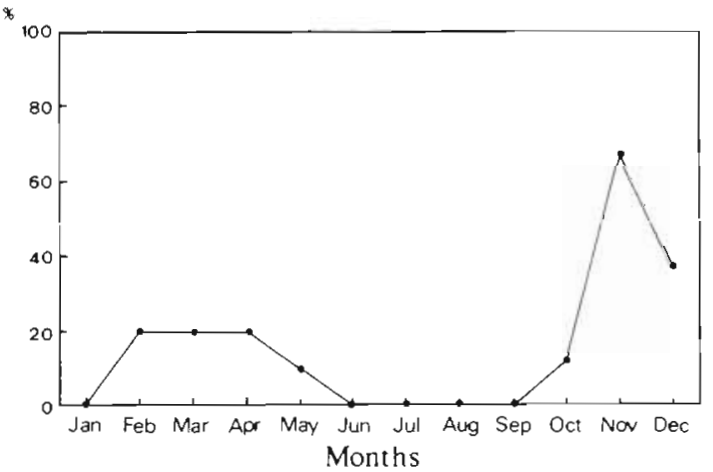

Fig. 10. Dicentrarchus labrax. Seasonal variations in rate of infection by Ichthyophonus sp. in wild sea bass

Severe cases of ichthyophoniasis reported by Couch (1985) also occurred in the coldest period of the year in an area (the Gulf Coast of Mexico) that experiences high summer temperatures. In fact, in vitro experiments have demonstrated that Ichthyophonus sp. can grow between 3 and $20^{\circ} \mathrm{C}$ but that its optimum temperature occurs at ca $10^{\circ} \mathrm{C}$ (Lauckner 1984).

(2) Prevalence and sex of the host. Prevalence was higher for both wild and cultured males than for females, but this difference was only statistically significant for cultured fish (Table 1). The findings suggest that females may be more resistant to infection, as has been suggested for some parasitic infections (Thomas 1964).

(3) Prevalence and age of the host. An increase in the prevalence and intensity of infection with the age of the host was observed. This was especially evident for cultured fish where differences between age classes were statistically significant (Table 2). This observation suggests that the infection spreads horizontally and that it tends to persist once it occurs.

Host pathology: Although affected fish did not exhibit external signs of disease, gross signs of infection were evident internally in tissues such as heart and muscle. Well-vascularised organs were the most frequently infected in wild and cultured sea bass (Fig. 11), a fact that has already been reported in other fish (McVicar \& McLay 1985, Paperna 1986).

Histopathologically, our fish showed the classic picture described for ichthyophoniasis in a variety of other hosts, i.e. the presence of granulomas (with an intense fibrotic reaction) that results in the encapsulation of the

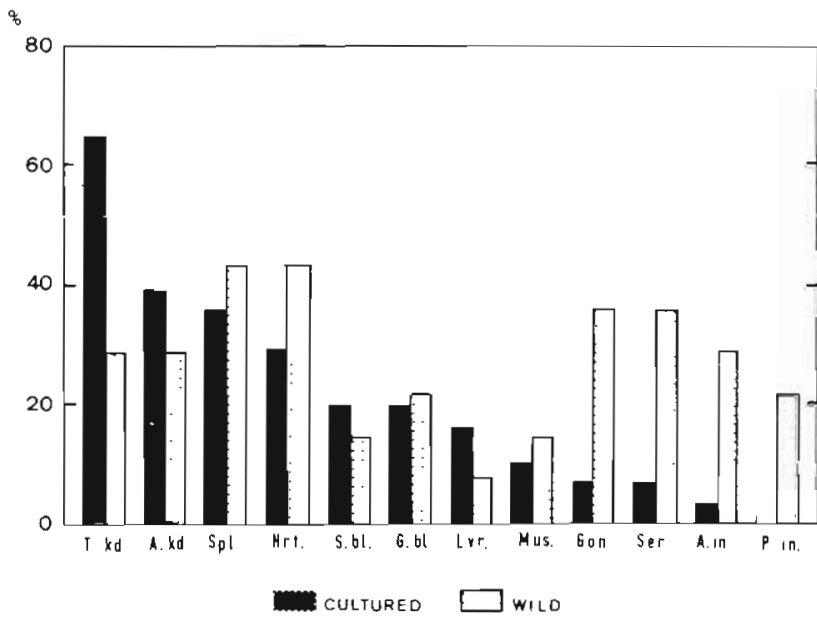

Fig. 11. Dicentrarchus labrax. Percentage of organs infected by Ichthyophonus sp. in wild and cultured sea bass. T.kd. trunk kidney; A. kd.: anterior kidney; Spl : spleen; Hrt.: heart; S. bl.: swim bladder; G. bl.: gall bladder; Lvr.: liver; Mus.: muscle; Con.. gonad; Ser.: serosa; A. in.: anterior intestine, $P$.in.: posterior intestine

Table 2. Dicentrarchus labrax. Influence of age in wild and cultured sea bass on the rate and intensity of infection by Ichthyophonus $\mathrm{sp}$. Asterisk indicates statistically significant differences at $p=0.05$

\begin{tabular}{lccc} 
Group & $\begin{array}{c}\text { Age class } \\
\text { (years) }\end{array}$ & $\begin{array}{c}\text { Prevalence } \\
(\%)\end{array}$ & Intensity \\
Wild & 3 & 9.52 & + \\
& 4 & 18.18 & ++ \\
& $>4$ & 40.00 & ++ \\
Cultured & $\leqslant 1$ & 17.80 & + \\
& 2 & 12.20 & ++ \\
& 3 & 50.00 & ++ \\
& $\geqslant 4$ & 55.50 & ++++ \\
\hline
\end{tabular}

parasite. Tissue damage was especially severe in the trunk kidney of some young fish $(0+)$, where extensive areas appeared affected (Figs. 12 to 17). The parasitized kidney tubules showed enlargement of the basal membranes, deposition of fibrotic tissue, and a certain degree of leucocytic infiltration with the presence of eosinophilic cells. Furthermore, spore-free tubules adjacent to infected ones showed hyaline- 

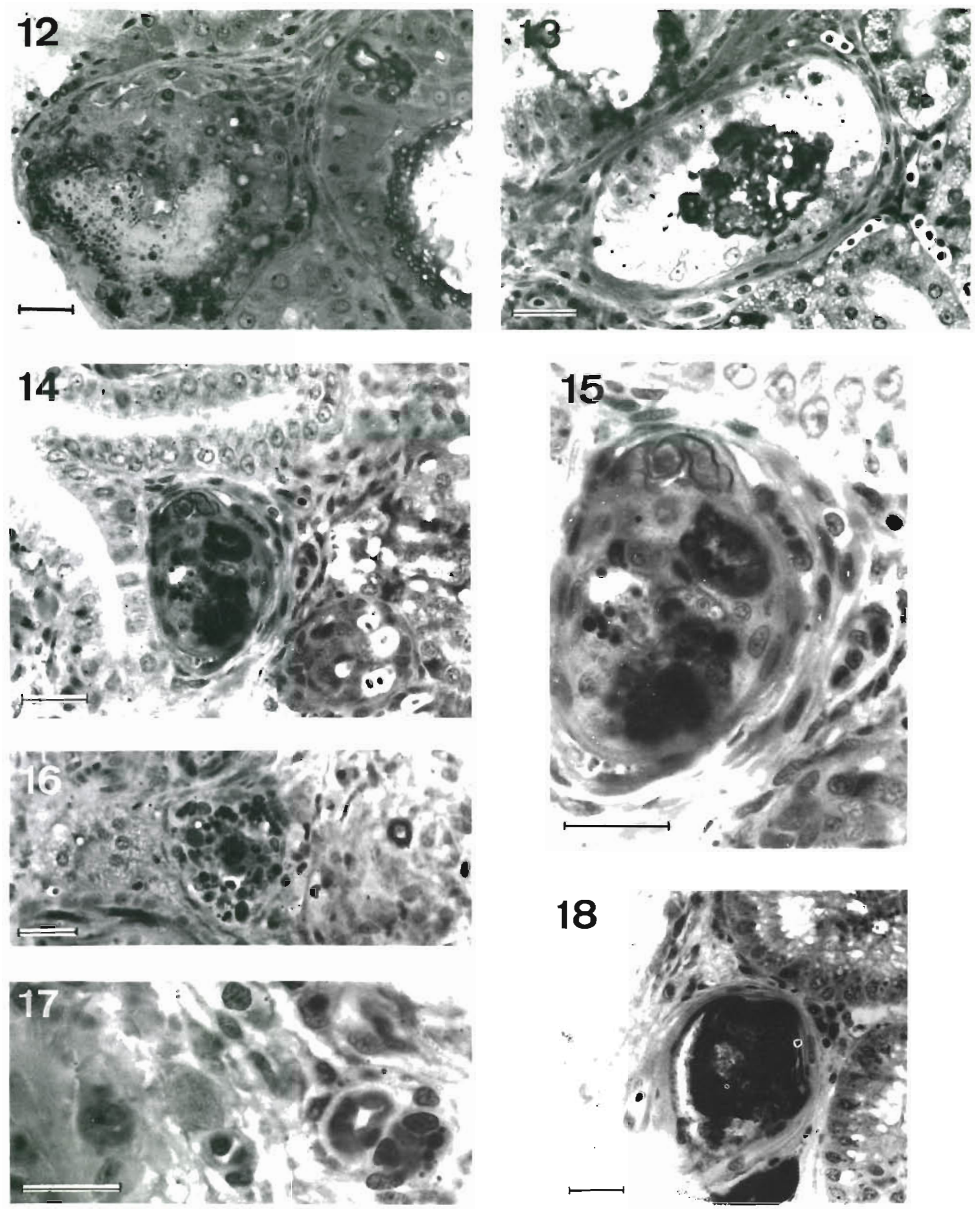

Figs. 12 to 18. Dicentrarchus labrax. Trunk kidney sections of sea bass $(0+)$ stained with toluidine blue showing Ichthyophonus sp. parasite stages in the epithelium (Fig. 12) and lumen (Fig. 13) of the tubuli, and in the interstitia (Figs. 13 to 17). Note the fibrotic reaction around a necrotic granuloma (Fig. 18). Scale bars $=20 \mu \mathrm{m}$ 
droplet degeneration of the epithelium (Fig. 13). Developing granulomas located in the interstitia were also observed (Figs. 14 and 15), and epithelioid cells were seen between the spores and fibroblasts.

In advanced or chronic infections, there was considerable deposition of pigment and necrotic material in affected tissues, and many spores seemed to be degenerate, as indicated by the loss of their wall integrity and the vacuolation and fragmentation of their cytoplasm (Fig. 18). In these cases, the lesions produced by the parasite replaced much of the normal tissues.

The observed inflammatory response was similar to that described by McVicar \& McLay (1985) for other hosts. They pointed out that the extent of the fibrotic reaction seemed to be correlated with the host's success in containing the infection. As in these hosts, the sea bass fibrotic response probably also assisted in restricting the formation of new infective stages.

Ichthyophoniasis is of considerable economic concern because it is capable of producing mortalities of epizootic proportions in wild marine fish populations (Cox 1916, Fish 1934, Sindermann 1970, McVicar 1982) and in fresh and seawater cultures (Rucker \& Gustafson 1953, Miyazaki \& Kubota 1977, Chien et al. 1979). Many different families of fishes are affected including Serranidae from the Mediterranean Sea (Reichenback-Klinke 1973). However, our finding of the infection in sea bass is a first for this species and underlines the importance of ichthyophoniasis in marine fishes, especially under culture conditions. Therapy for ichthyophoniasis is not available, but our results on infection dynamics suggests that management could help in controlling the disease. More detailed studies on the biology of this destructive parasite and on the host's defense mechanisms against it, are necessary if ichthyophoniasis in farmed fish is to be controlled or prevented.

Acknowledgements. We thank Dr S. Zanuy und Dr M. Carillo of the I.A.T.S. for providing the host specimens and their facilities. This investigation was supported by a research grant (AC26/84) from CAICYT, Spain.

\section{LITERATURE CITED}

Agius, C. (1978). Infection by an Ichthyophonus-like fungus in the deep-sea scabbard fish Aphanus carbo (Lowe) (Trichiuridae) in the North East Atlantic. J. Fish Dis. 1. 191-193

Chien, C., Miyazaki, T., Kubota, S. S. (1979). Studies on Ichthyophonus disease of tishes. IV Comparative study on naturally infected fishes. Bull. Fac. Fish. Mie Univ. 6: $219-246$

Responsible Subject Editor: Dr T Evelyn, Nanaimo, B. C., Canada
Couch, J. A. (1985). Prospective study of infectious and noninfectious disease in oysters and fishes in three Gulf of Mexico estuaries. Dis. aquat. Org. 1: 59-85

Cox, P. (1916). Investigation of a disease of the herring (Clupea harengus) in the Gulf of S. Lawrence, 1914. Contr Can. Biol. Fish. 1914-1915: 81-85

Fish, F. F (1934). A fungus disease in fishes of the Gulf of Maine. Parasitology 26: 1-16

Hendricks, J. D. (1972). Two new host species for the parasitic fungus Ichthyophonus hoferi in the Northwest Atlantic. J. Fish. Res. Bd Can. 29: 1776-1777

Hofer, B. (1893). Eine Salmoniden-Erkrankung. Allg. FischZtg. 18: 168-171

Lauckner, G. (1984). Diseases of Pisces. Diseases caused by Microorganisms. Agents: Fungi. In: Kinne, O. (ed.). Diseases of marine animals, Vol. IV, Part 1, Pisces. Biologische Anstalt Helgoland, Hamburg, p. 89-113

McVicar, A. H. (1982). Ichthyophonus infection in fish. In: Roberts, R. J. (ed.) Microbial diseases of fish. Academic Press, London, p. 243-269

McVicar, A. H., McLay, H. A. (1985). Tissue response of plaice, haddock and rainbow trout to the systemic fungus Ichthyophonus. In: Ellis, A. E. (ed.) Fish and shellfish pathology. Academic Press, London, p. 329-346

Miyazaki, T., Kubota, S. (1977). Studies on Ichthyophonus disease of fishes. I. Rainbow trout fry. Bull. Fac. Fish. Mie Univ. 4: 45-56.

Neish, G. A., Hughes, G. C. (1980). Fungal diseases of fishes. In: Snieszko, S. F., Axelrod, H. R. (eds.) Diseases of fishes, Book 6. T.F.H. Publications, New Jersey

Okamoto, N., Nakase, K., Suzuki, H., Nakai, Y., Fujii, K. Sano, T (1985). Life history and morphology of Ichthyophonus hoferi in vitro. Fish Path. 20: 273-285

Okamoto, N., Suzuki, H., Nakase, K., Sano, T (1987) Experimental oral infection of rainbow trout with spherical bodies of Ichthyophonus hoferi cultivated. Nippon Suisan Gakk. 53: $407-409$

Paperna, I. (1986). Ichthyophonus infection in grey mullets from Southern Africa: histopathological and ultrastructural study. Dis. aquat. Org. 1: 89-97

Plehn, M., Mulsow, K. (1911). Der Erreger der Taummelkrankheit der Salmoniden. Zent. Bakt. ParasitKde 58: 63-68

Powles, P. M., Garnett, D. G., Ruggieri, S. J., Nigrelli, R. F. (1968). Ichthyophonus infection in yellowtail flounder (Limanda ferruginea) off Nova Scotia. J. Fish. Res. Bd Can. 25: $597-598$

Reichenback-Klinke, H. H. (1973). Fungi and algae as fish parasites. In: Fish pathology. T.F.H. Publications, New Jersey, p. 102-124

Rucker, R. R., Gustafson, P. V (1953). An epizootic among rainbow trout. Prog. Fish Cult. 15: 179-181

Sindermann, C. J. (1970). Principal diseases of marine fish and shellfish. Academic Press, New York

Sokal, R. R., Rohlf, F. J. (1981). Biometry. Freeman \& Co., New York

Thomas, J. D. (1964). A comparison between helminth burdens of male and female brown trout Salmo trutta L. from a natural population in the River Teify, West Wales. Parasitology 54: 263-272.

Timur, G., Timur, M. (1984). Giant-cell reaction associated with Ichthyophonus hoferi infection in wild plaice, Pleuronectes platessa L. J. Fish Dis. 7: 513-514

Manuscript first received: April 20, 1989

Revised version accepted: February 22, 1990 